\title{
Incentivos institucionales para caminos rurales (Buenos Aires, mediados del siglo XX)
}

\author{
Incentivos institucionais para estradas rurais (Buenos Aires, \\ meados do século XX)
}

\section{Institutional incentives for rural roads (Buenos Aires, mid-20 th century)}

Alejandra Laura Salomon ${ }^{*}$

\begin{abstract}
Resumen
El papel de la infraestructura en el desarrollo rural ha recibido creciente atención en el debate público y académico, en base al consenso de que las deficiencias obstaculizan el bienestar social y al crecimiento económico. En la Argentina, estas deficiencias se advierten en los caminos rurales. Bajo el supuesto de que éstos constituyen un recurso de uso común, en este trabajo nos centraremos en el sistema de consorcios camineros, una de las soluciones institucionales que cobró auge a fines de la década de 1950 en la provincia de Buenos Aires. Para ello, analizaremos desde una perspectiva histórica y en base a la investigación documental (legislación, publicaciones periódicas, informes técnicos, memorias gubernamentales, etc.), sobre los incentivos institucionales que habrían potenciado los esfuerzos comunitarios por resolver problemas viales.
\end{abstract}

Palabras clave: caminos rurales, instituciones, consorcios camineros, Argentina, perspectiva histórica.

\section{Resumo}

O papel da infraestrutura no desenvolvimento rural tem recebido crescente atenção no debate público e acadêmico, baseado no consenso de que as deficiências dificultam o bem-estar social e o crescimento econômico. Na Argentina, essas deficiências são vistas em estradas rurais. Sob o pressuposto de que estes constituem um recurso de uso comum, neste trabalho vamos nos concentrar no sistema de consórcios rodoviários, uma das soluções institucionais que ganhou força no final dos anos 1950 na província de Buenos

\footnotetext{
* Doctora en Ciencias Sociales y Humanidades (Universidad Nacional de Quilmes), Profesora en Historia (Universidad de Buenos Aires), Investigadora Adjunta del CONICET.E-mail: alejandralaurasalomon@gmail. com
} 
Aires. Para isso, analisaremos a partir de uma perspectiva histórica e com base em pesquisa documental (legislação, periódicos, relatórios técnicos, relatórios governamentais, etc.) sobre os incentivos institucionais que teriam fortalecido os esforços da comunidade para resolver os problemas da estrada. Palavras-chave: estradas rurais, instituições, consórcios rodoviários, Argentina, perspectiva histórica.

\begin{abstract}
The role of infrastructure in rural development has received increasing attention in the public and academic debate, provided that its deficiencies affect social well-being and economic growth. In Argentina, these weaknesses are evident in rural roads. Accepting that they constitute a common-pool resource, in this paper we will examine local consortium, one of the institutional solutions that proliferated at the end of the decade of 1950 in the province of Buenos Aires. For it, we will analyze, from a historical perspective and on the basis of documents (legislation, press, technical reports, government reports), on the institutional incentives that would have promoted the community efforts for solving road problems.
\end{abstract}

Key words: rural roads- institutions- consortium- Argentina- historical perspective.

\title{
1.Introducción
}

En los últimos tiempos el papel de la infraestructura en el desarrollo rural ha recibido creciente -aunque aun insuficiente- atención en el debate público y académico, en base al consenso de que las deficiencias en la cantidad y calidad obstaculizan el bienestar social y el crecimiento económico. ${ }^{1}$ En la Argentina, estas deficiencias se advierten con facilidad en los caminos rurales, los que son normalmente de tierra, no están inventariados y padecen un alto grado de intransitabilidad durante buena parte del año.

Siguiendo a Ostrom, podría plantearse que éstos constituyen un recurso de uso común (RUC), en tanto sistema de recursos creado por el hombre, lo suficientemente grande para volver costoso excluir a beneficiarios potenciales

\footnotetext{
${ }^{1}$ Entre otros, véanse: FUNDACIÓN AGROPECUARIA PARA EL DESARROLLO DE ARGENTINA. Caminos rurales en las provincias argentinas. Análisis y soluciones, Río Cuarto, 2017. CORPORACIÓN ANDINA DE FOMENTO. Caminos para el futuro. Gestión de la infraestructura en América Latina. Caracas, 2009. BANCO MUNDIAL. Infraestructuras Rurales en Argentina. Diagnóstico de Situación y Opciones para su Desarrollo. Reporte № 39493, abril de 2007.
} 
y sumido a la sobreutilización debido al uso más intenso que el apropiado. ${ }^{2}$ Esto supone que la existencia de individuos interactuando entre sí para la explotación del recurso -es este caso, el uso y la conservación de caminos-, plantea un problema social. Tanto los beneficios como los costos de tomar acciones individuales afectan el bienestar social.

Bajo este supuesto, en el presente trabajo pretendemos abrir la discusión sobre opciones institucionales para resolver dilemas asociados a la vialidad en espacios rurales. Si bien en la Argentina los caminos rurales pueden estar construidos, conservados o mejorados por municipios, entidades viales provinciales o consorcios camineros (CC), las evidencias indican que este último sistema, al conjugar los esfuerzos de los sectores público y privado, constituye una de las soluciones institucionales más convenientes para hacer frente a la planificación, la gestión y al control de las obras. En su doble rol de productores y apropiadores del RUC, los CC se erigen como valiosas asociaciones sin fines de lucro con caracter público (por los fines que persigue y las prerrogativas que recibe) que colaboran con el Estado y se sustentan y a la vez fomentan el capital social, en base al trabajo colaborativo con anclaje local. ${ }^{3}$ En el marco de arreglos institucionales, determinados rasgos de una comunidad podrían explicar la disposición a cooperar de los individuos, tales como la confianza, la reciprocidad y la reputación.

Varios trabajos, por lo general a cargo de ingenieros, exhiben la diversidad de experiencias actuales en la gestion y el manteniemiento de los caminos rurales argentinos. ${ }^{4}$ Pero, lo que falta en la caja de herramientas de los estudiosos es una teoría de la acción coletiva que permita explicar y tal vez predecir los límites y capacidades de las iniciativas de autoorganización y autogestión, dentro de una matriz histórica. A mediados del siglo XX, se observa la proliferación de CC

\footnotetext{
${ }^{2}$ OSTROM, Elinor. El gobierno de los bienes comunes. La evolución de las instituciones de acción colectiva. FCE/ UNAM. México, 2017, p. 77.

${ }^{3}$ OSTROM, Elinor y AHN, T. K.. “Una perspectiva del capital social desde las ciencias sociales: capital social y acción colectiva”. En Revista Mexicana de Sociología. Año 65, № 1. 2003, pp. 155-233. Disponible en: http:// www.biblioteca.org.ar/libros/92258.pdf

${ }^{4}$ Entre otros: GAGO, Julio. "Caminos rurales terciarios. Hacia un cambio profundo en la gestión de su conservación". Ponencia presentada en el XIV Congreso Argentino de Vialidad y Tránsito. Buenos Aires, 26 al 30 de septiembre de 2005. Disponible en: https://es.scribd.com/document/33765836/CAMINOS-RURALESTERCIARIOS. BARDELLI, María Guadalupe, DONATELLI, Miguel y MORENO, Evangelina. "Desarrollo de caminos rurales orientados a la productividad". Ponencia presentada en el XVII Congreso Argentino de Vialidad y Tránsito. Rosario, 24 al 28 de octubre de 2016. Disponible en: http:///congresodevialidad.org.ar/TRA/ TRA-007.pdf. FUNDACIÓN AGROPECUARIA PARA EL DESARROLLO DE ARGENTINA, op. cit.
} 
¿Cómo han operado los arreglos institucionales para potenciar la conformación de CC a mediados del siglo XX? ¿Por qué algunos esfuerzos por resolver problemas viales fracasaron desde el último cuarto del siglo XX (provincia de Buenos Aires), mientras que otros tuvieron más éxito (por ejemplo, las provincias de Córdoba ${ }^{5}$ Chaco)? ¿Qué podemos aprender de la experiencia que ayude a estimular el desarrollo y uso de una mejor teoría de la acción colectiva, para identificar las variables clave que han imulsado o mermado las capacidades de los individuos para resolver los problemas viales?

A la luz de las experiencias, tomaremos el caso de las no abordadas académicamente las asociaciones voluntarias y solidarias de vecinos de la provincia de Buenos Aires, las cuales luego de haber proliferado a fines de los años cincuenta y durante los sesenta, ingresaron por la senda del declive y actualmente intentan ser reconstruidas por los poderes públicos. A fin de iniciar la comprensión de tal derrotero, reflexionaremos desde una perspectiva histórica y en base a la investigación documental (legislación, publicaciones periódicas, informes técnicos, memorias gubernamentales, etc.) sobre los incentivos institucionales que habrían potenciado los esfuerzos de las comunidades bonaerenses -plasmados en la conformación de CC- por resolver problemas viales a mediados del siglo XX, con la pretensión de entablar un diálogo entre el pasado y el presente que permita identificar variables que convendrían ser incluidas a la hora de diagramar políticas públicas. Puntualmente, analizamos la contribución de políticas públicas en materia vial que entre 1956 y 1977 dieron reconocimiento e impulso a los CC, con el foco colocado en la provincia de Buenos Aires. En este sentido, un supuesto que alimenta la hipótesis es que son las instituciones las que determinan las posibilidades de desarrollo, al crear incentivos a la inversión en capital físico y humano. ${ }^{6}$

\section{Los caminos rurales como recurso de uso común. El caso de la provincia de Buenos Aires a mediados del siglo XX}

Históricamente, la red vial argentina se concibió en base a un marcado sesgo radial con su epicentro en Buenos Aires, como puerto de exportación e inportación y como punto de confluencia de las capitales de provincias. Esta

\footnotetext{
${ }^{5} \mathrm{El}$ caso cordobés ha sido trabajado por CIVITARESI, Martín. "Caminos rurales, consorcios camineros y desarrollo regional en la provincia de Córdoba (Argentina) en la segunda mitad del siglo XX". En Tiempo y Economía, 5 (2), 2018, pp. 89-105. Disponible en: https://revistas.utadeo.edu.co/index.php/TyE/issue/ view/114/PDFa.

${ }^{6}$ NORTH, Douglas. Instituciones, cambio institucional y desarrollo económico. FCE. México, 1995.
} 
red, de jurisdicción nacional, ha sido diseñada, construida y mantenida por el gobierno nacional a través de la Dirección Nacional de Vialidad (DNV). Las necesidades de integración nacional y de vinculación de zonas de producción y de turismo impulsaron la red secundaria, la que se conecta con la red primaria y comprende las vías que unen las cabeceras municipales entre sí junto con los accesos a las mismas. Su construcción y conservación es responsabilidad de las Direcciones Provinciales de Vialidad. Por último, la red terciaria, también denominada vecinal, municipal o comunal, está integrada por los caminos cuya titularidad y competencia es de los municipios. La más extensa de las tres y definida por exclusión (es decir, no pertener a las anteriores), constituye el eslabón más frágil, por ausencia de un relevamiento integral, políticas de largo plazo, recursos y matenimiento sistemático.

Dentro de la red vial, los caminos rurales son aquellos que permiten el acceso a las explotaciones agropecuarias y que corresponden a las redes viales secundaria y, principalmente, terciaria. Bajo control provincial o municipal, cumplen un importante rol en el desarrollo de las actividades productivas y en la mejora de la condiciones de vida de la población rural. En un país de vastas dimensiones, con una deficiente infraestructura ferroviaria y un débil peso de las vías fluviales, estimulan la generación de oportunidades productivas, reducen los costos de trasporte y transacción y mejoran el acceso a los mercados. De hecho, los camiones son responsables de la mayor cantidad de cargas, aunque paradójicamente enfrentan enormes dificultades en cuanto a la infraestructura. Pero los caminos rurales no sólo constituyen elementos indispensables para la producción y comercialización de los productos agropecuarios, sino que amplían las posibilidades de generación de ingresos de los hogares y fortalecen la vida comunitaria, la comunicación, el consumo y el acceso a la educación y a la salud. No obstante, su déficit es de larga data, y continúan desde hace décadas relegados de la agenda pública.

Sobre la base de la definición de RUC, partimos de la premisa de que los caminos rurales plantean el desafío de encontrar mecanismos para lograr procesos de acción colectiva, en pos de una construcción planificada y un uso eficiente y sostenible en el tiempo. Como cualquier otro RUC, así como son colectivos sus beneficios (aunque no todos colaboraren en la conservación), también son colectivos los costos de tomar acciones individuales que deterioren su estado (por ejemplo, transitar en días de intensa y/o continuada lluvia o con carga excesiva). Por ende, ningún productor agropecuario se mantiene ajeno a los problemas sociales y económicos derivados de la explotación de este RUC. Es decir, no resulta suficiente construir un camino, sino que éste 
exige un uso racional y un cuidado permanente, en base al concepto de que constituye un recurso que se paga, se gestiona y se utiliza entre todos. A juzgar por las experiencias, ceder a los actores locales el protagonismo en la gestión puede ser una manera de motorizar la acción ciudadana. De modo que para una resolución colectiva de la problemática, resulta promisoria la adopción de estrategias cooperativas en el marco de arreglos institucionales que promuevan el asociacionismo. Eso ocurrió a partir de 1956, en un contexto en que diversos planes gubernamentales y leyes marcaron un hito en la política pública respecto a los caminos rurales. ${ }^{7}$

Para dar cuenta de dicho contexto, conviene destacar la importancia de los caminos rurales en la provincia de Buenos Aires, la cual detenta un lugar central dentro de la estructura productiva del país. Con una superficie de $301.571 \mathrm{~km} 2$, tradicionalmente se ha desempeñado como la principal provincia generadora de riqueza agropecuaria. A pesar del crecimiento industrial desplegado hacia 1930, cereales y carne siguieron ocupando los primeros lugares dentro del rubro exportación.

Ya desde el siglo XIX, la infraestructura en transportes y comunicaciones evidenciaba una alta concentración en la zona metropolitana. Hacia la ciudad de Buenos Aires -y en menor medida hacia Rosario y Bahía Blanca- confluían la mayor parte de las redes viales y ferroviarias, delienando un esquema radial perjudicial para la intercomunicación de las localidades del interior. En el campo, el auge del modelo agroexportador propició, con el tendido de las líneas de transporte, la conglomeración de población en torno a cruces de caminos, grandes estancias y en particular alrededor de las estaciones ferroviarias. Estos pueblos fueron céculas activas y funcionales de un modelo económico funcional a los interses agropecuarios.

A mediados del siglo XX, se impuso un hito en la cuestión demográfica rural. Según información censal, de un 28,6\% en 1947 pasó a un 13\% en 1960, producto del intenso éxodo rural, tendencia originada previamente pero agudizada en esos años. Las razones de este fenómeno son múltiples. La modernización del agro bonaerense trajo aparejado una importante

\footnotetext{
${ }^{7}$ Con anterioridad, se habían implementado otras iniciativas, pero su caracter fue parcial y transitorio. En 1907 y hasta 1947, la ley 5.325 -conocida como Ley Mitre-, dispuso una contribución del 3\% de los ingresos de las empresas ferroviarias para la construcción y el mantenimiento de los caminos de acceso a las estaciones. Se creó un fondo específico que primero administró una Comisón de Caminos autárquica y en 1925 pasó a integrar la Dirección de Puentes y Caminos. Pero la falta de coordinación de las políticas, la declinación de los ingresos de las compañías y luego la caducidad de la ley hicieron que el desarrollo de los caminos municipales quedara librado al esfuerzo del vecindario, de las comisiones de fomento y de los Intendentes.
} 
mutación en la vida rural y en las relaciones con el espacio. ${ }^{8}$ Por un lado, la tecnificación del agro generó un marcado descenso en las necesidades de mano de obra, la cual fue absorbida principalmente por la demanda de trabajo generada por las industrias urbanas. Por otro, muchos productores reemplazaron paulatinamente las labores físicas por las gerenciales, delineando un nuevo perfil que se definía como profesional y descalificaba el modo de vida rural. La mayor capitalización y la difusión de nuevas pautas de consumo que los asemejaban a los sectores medios urbanos, en combinación con la desvalorización de los productos elaborados por la propia familia o comunidad, los involucró cada vez más en el mercado. No sólo el deseo de bienes de consumo masivo, la participación de alguna actividad cultural o de esparcimiento, la visita al médico, el abastecimiento de insumos o la reparación de maquinarias más complejas incrementaron la frecuencia de los viajes a las ciudades (de una o dos veces al mes a dos o tres veces por semana), sino también motivaron el abandono de la explotación como residencia permanente. ${ }^{9}$ Así, los pequeños pueblos dejaron de ser centros de la vida social agraria y las ciudades-cabecera de los distritos ocuparon su lugar como espacios de sociabilidad.

La pérdida de población de las pequeñas localidades y el deterioro de la prestación de servicios públicos -como las comunicaciones y los transportespotenciaron el aislamiento territorial en paralelo al crecimiento de la población urbana. En especial, el problema de la accesibilidad se visualizó como un problema experimentado en pequeñas localidades a partir de la desafectación, cierre o clausura de los servicios ferroviarios. ${ }^{10}$ Comenzó a perfilarse así un drama que azota actualmente a muchos pueblos rurales: la amenaza de extinción. ¿Qué papel ha jugado en la despoblación la falta de infraestructura básica? Para el caso de la vialidad, prevalecen las preguntas antes que certezas basadas en evidencias empíricas. ¿Hasta qué punto un camino asfaltado favorece el arraigo o, por el contrario, facilita el acceso a la ciudad y desalienta la vida rural, convirtiendo a la explotación agropecuaria,

\footnotetext{
${ }^{8}$ ALBALADEJO, Christophe. "Dinámica de la inserción territorial de la agricultura pampeana y emergencia del agribusiness". En GRAS, Carla y HERNÁNDEZ, Valeria (Comps.), El agro como negocio: Producción, Sociedad y Territorios en la Globalización. Biblos. Buenos Aires, 2017. Disponible en: https://hal.archives-ouvertes.fr/ hal-01585737/document.

${ }^{9}$ BALSA, Javier. El desvanecimiento del mundo chacarero. Transformaciones sociales en la agricultura bonaerense, 1937-1988. UNQ. Bernal, 2006.

${ }^{10}$ DIEZ TETAMANTI, Juan Manuel. "Cambios en los sistemas de transporte asociados al problema de exclusión socio-territorial en pequeñas localidades”. En Párrafos Geográficos, 12, № 1, 2013. SILI, Marcelo. Los espacios de la crisis rural. Geografía de una pampa olvidada. Ed. UNS. Bahía Blanca, 2000.
} 
a lo sumo, en un mero espacio de trabajo diurno? ¿Qué rol ha asumido la conectividad vial en el hecho de que el campo ya no sea un lugar de residencia permanente? Estos interrogantes, sugeridos en varios trabajos, ameritarían estudios históricos específicos sobre el impacto real de la apertura, la pavimentación y el mejoramiento de caminos. ${ }^{11}$ Persisten múltiples lagunas sobre la política vial durante la segunda mitad del siglo XX y su impacto en la actividad productiva y en las condiciones de vida rural.

A mediados de la década de 1950 los datos estadísticos indican que en la provincia de Buenos Aires, sobre $109.169 \mathrm{~km}$ de caminos en total, los de jurisdicción municipal ascendían aproximadamente a $65.000 \mathrm{~km}$, es decir, representaban el 59,54\% y eran casi completamente de tierra. ${ }^{12}$ La precariedad de su estado, tal como se advierte en fuentes periodísticas locales y en los debates legislativos, se debía al exceso de cargas de transporte, la erosión hídrica y la falta de mantenimiento permanente, por lo que pese a que el tránsito no era tan abundante como en las ciudades, estaban afectados por la sobreutilización. ${ }^{13}$ Como agravante, debe tenerse en cuenta que la declinación del servicio ferroviario durante las dos décadas anteriores obró a favor de la relevancia del transporte por camión, "de puerta a puerta". Ello determinó que las cargas fueran mayores y, por ende, más imperiosa la actividad de manteniemiento de caminos, en un contexto en el que crecían el parque automotriz y el "hábito de transitar". Estos problemas se tornaban más notorios a raíz del anegamiento por lluvias y las inadecuadas obras de regulación hídrica en los campos, provocando la intransitabilidad y mayores costos para los productores.

Si bien había disposiciones que reglaban el uso de los caminos en la provincia, al quedar desactulizadas y no contar con un efectivo control gubernamental pocas veces eran respetadas. ${ }^{14}$ Regía, por un lado, la prohibición de circular por caminos de tierra vehículos pesados (incluidos tractores) hasta tres días después de la última lluvia y siempre y cuando la calzada se encontrara suficientemente oreada, salvo permiso especial. Por otro, estaba estipulado el peso máximo de los vehículos a propulsión

\footnotetext{
${ }^{11}$ BALSA, Javier, op. cit. BENÍTEZ MARTÍNEZ, Marcela. La Argentina que desaparece. Desintegración de comunidades rurales y poblados en vías de desaparición. Tesis de Doctorado. Universidad de Belgrano. Buenos Aires, 1998. ${ }^{12}$ PETRIZ, Pedro. “La vialidad provincial en Buenos Aires”. En Carreteras. № 11, julio-septiembre de 1967. ${ }^{13}$ SALOMÓN, Alejandra. "Un lazo ausente: política vial y condiciones de vida en ámbitos rurales de la provincia de Buenos Aires (Argentina, 1940-1950)". En Revista Brasileira de História \& Ciências Sociais- RBHCS, Vol. 9, № 18: 16-35. Disponible en: https://www.rbhcs.com/rbhcs/article/view/445/www.latindex.org/ ${ }^{14}$ Por ejemplo, tanto la Ley de Caminos, Cercas y Tranqueras (1889) como el Código Rural (1865) rigieron durante toda la primera mitad del siglo XX.
} 
mecánica o remolcados, de acuerdo a la cantidad de ejes. A esto debe añadirse la obligación de contribución vecinal en cuanto al mantenimiento libre de cunetas, alcantarillas y desagues frente a las tranqueras y el cuidado del alambrado en perfecto estado para evitar la suelta de animales. Pero la inobservancia de la reglamentación generaba inconvenientes y tensiones entre los usuarios, tal como aparece en los congresos viales y la prensa local. En tanto que la escasa cantidad de inspectores, la desactualización de las multas y la disparidad e inexistencia de disposiciones municipales perjudicaba el contralor gubernamental. El resultado saltaba a la vista: los caminos, una vez construidos, adolecían de un ciudado permanente.

Hacia 1962, se estimaba que si se calculaba el recorrido de un camión en un camino en buen estado y otro en mal estado, el índice de transitabilidad era de un $70 \%$ y $50 \%$ respectivamente, mientras que la velocidad promedio aumentaba en un $40 \%$ y el costo de circulación se incrementaba en un $29 \%$ en el segundo caso. ${ }^{15} \mathrm{~A}$ su vez, la intransitabilidad que el efecto climático provocaba en caminos ya desgastados causaba efectos colaterales: el aumento de precios de los productos agropecuarios. ${ }^{16}$ En otras casos eran los pueblos mismos los que estaban en jaque, tal como alertaba la revista Noticias Camineras:"Carlos Keen, un pueblo que se extingue por la falta de caminos". ${ }^{17}$

Pese a la relevancia económica y social de este RUC y a que conformaba más de la mitad del sistema vial, recibía una magra parte del presupuesto, en contraste con otros países americanos. ${ }^{18}$ De acuerdo al director de la DNV, el equipo de las comunas bonaerenses para la conservación servía una magra porción de las necesidades normales. En 1960, el mismo podía estimarse entre en 10 y el 15\% de las necesidades normales. ${ }^{19}$ La falta de materiales, personal capacitado y dinero desalentaba cualquier esfuerzo en las localidades, pues el foco de atención provincial estaba colocado exclusivamente en carreteras de

\footnotetext{
${ }^{15}$ VILLAR, Juan. El camino de tierra y su circunstancia bonaerense. 1962, p. 175.

${ }^{16}$ Noticias Camineras. № 51, julio de 1958, p. 1.

${ }^{17}$ Noticias Camineras. № 40 , agosto de 1957, p. 4.

${ }^{18} \mathrm{La}$ experiencia en otros países americanos señalaba que en Brasil, por ejemplo, el gobierno federal distribuía el Fondo Nacional de Vialidad entre la Unión (40\%), los Estados (48\%) y los Municipios (12\%) e imponía la coordinación de los planes de desarrollo de las tres redes. En Estados Unidos los gobiernos locales recibían para calles y caminos alrededor del 25\% de los fondos estaduales; la inversión en caminos rurales era del 20\% de la inversión total en obras viales. México, por su parte, estableció en 1949 el Comité Nacional de Comunicaciones Vecinales dotado de recursos específicos que se dedicaba a construir caminos, aeropuertos, teléfonos y telégrafos de tipo vecinal. Por terceras partes aportaban el costo de las obras los usuarios, el Estado y el Comité, el que a su vez las proyectaba y dirigía. Un $18 \%$ de los fondos viales se invertían en los caminos vecinales. DNV. Conferencias sobre temas viales. Vol. 51, Buenos Aires, 1960, p. 17. ${ }^{19}$ Ibidem, p. 13.
} 
bajo costo que conectaban centros estratégicos, en términos poblacionales, productivos o turísticos. En cambio, escaso interés recibió en la agenda pública la vinculación de pequeños poblados o explotaciones agropecuarias.

Si bien la red de menor jerarquía, la municipal, comunal o vecinal, constituía una atribución de los Municipios, a éstos no se los dotaba de recursos suficientes. Gozaban de una reducida participación en la percepción impositiva provincial y contaban con escasos fondos propios en concepto de rentas e impuestos municipales. la mayor parte de las Municipalidades, para reforzar las partidas destinadas a la obra vial municipal, solicitaban ayudas discrecionales al gobierno provincial o bien crearon un impuesto sobre la propiedad rural. El Dr. Bedacarratz, representante vial de la localidad de Adolfo Alsina, se quejaba: "En casi todos los distritos rurales hemos tenido que aplicar el impuesto a la tasa de campo, siempre con gran resistencia de un gran sector ganadero propietario que cree que en una sobreimposición de impuestos. A pesar de esas tasas que se han aplicado (...), la resistencia a pagarla siempre hace que se recaude un 40 o 50\%". ${ }^{20}$

En suma, el análisis documental indica que buena parte de la red vial que permitía llegar a los establecimientos agropecuarios se hallaba en estado regular, producto de varios motivos: mayores cargas de transporte, carencia de una legislación que ordenara la jurisdicción y estableciera las bases de una adecuada financiación, precariedad de conocimintos técnicos por parte de las personas encargadas de realizar la tarea y notoria escasez de elementos mecánicos destinados a su construcción y manteniemiento.

\section{Incentivos institucionales para los Consorcios Camineros}

El Plan de Caminos de Fomento Agrícola definió, por primera vez, una política nacional explicita de desarrollo de caminos rurales en 1956 (originariamente previsto para cinco años, luego fue extendido; rigió hasta 1977), en base a la colaboración entre la Nación, las provincias, los municipios y los propios interesados, cuando el crecimiento del transporte automotriz, el retroceso ferroviario y la expansión agraria plantearon la necesidad de dar organicidad al impulso de los caminos alimentadores de la red troncal. ${ }^{21}$ Al calor de la idealización de la modernización y del desarrollo, este Plan se implementó junto a otras políticas que revalorizaban el papel del agro, tales como la creación del Instituto Nacional de Tecnología Agropecuaria (INTA),

\footnotetext{
${ }^{20}$ Primer Congreso Vial Municipal de la Provincia de Buenos Aires. La Plata, 1961, p. 61.

${ }^{21}$ República Argentina. Boletín Oficial. Decreto-ley 9.875 del 8/6/1956, pp. 1-2.
} 
beneficios impositivos y créditos subsidiados a los productores, entre otras. ${ }^{22}$ Cabe agregar que la decisión con la que se encaró la cuestión de los caminos rurales no se debió solamente a un diagnóstico de la crisis, sino también a un proyecto de desarrollo nacional que consideraba que las carencias en materia de transportes constituían uno de los grandes obstáculos a la modernización de la empresa rural.

El Plan, al cual se acogió la provincia de Buenos Aires ${ }^{23}$, destinó el $40 \%$ de los fondos a las provincias para la construcción, mejoramiento y conservación de colectoras que se conectaran a las redes pavimentadas provinciales o nacionales, en tanto que el resto se dirigiría a CC para caminos de penetración directa a las chacras. Estas asociaciones ejecutarían y financiarían el 20\% del costo de las obras (con dinero, servicios o materiales) y contarían con la colaboración, la aprobación, la administración y el contralor de una Comisión Vial municipal creada a tal efecto. Para ser avalados, debían presentar junto al proyecto una estimación de costos y un plan de inversiones, con lo cual se deduce la necesidad de asesoramiento experto. Su constitución administrativa era simple y su caracter transitorio, puesto que su existencia dependía del cumplimiento de un objetivo puntual. De este modo, se les dio un esquema de financiamiento y organización a los caminos rurales, en tanto el contexto político-ideológico defendía el rol del Estado, la descentralización y la iniciativa privada como pilares del desarrollo. Lo ilustran los congresos, exposiciones y publicaciones, en los que ingenieros y académicos exaltaban el rol del municipio y de los vecinos en materia de vialidad, contribuyendo a la concepción de que ésta era un problema también local. ${ }^{24}$

Según datos de 1963, en la provincia de Buenos Aires, en relación al total del país, se formó la mayor cantidad de CC (745, es decir, 29,8\%), se emprendieron la mayor cantidad de obras (818, es decir, 28,2\%), se construyó la mayor longitud de caminos $(31.425,20 \mathrm{~km}$, es decir, 30,7\%) y se utilizó la mayor cantidad de presupuesto (21,8\%). ${ }^{25}$ A pesar de los avances, sólo el 5\% de la red de la provincia estaba pavimentada (Gráfico 1).

\footnotetext{
${ }^{22}$ ALTAMIRANO, Carlos. "Desarrollo y desarrollistas", Prismas, 2, 1998, pp. 75-94. BARSKY, Osvaldo y GELMAN, Jorge. Historia del agro argentino. Desde la conquista hasta comienzos del siglo XXI. Sudamericana. Buenos Aires, 2009.

${ }^{23}$ Ministerio de Gobierno de la Provincia de Buenos Aires. Registro Oficial. 1956, vol. VII, pp. 1.564-1.565.

${ }^{24}$ SALOMÓN, Alejandra. "Los caminos rurales desde una perspectiva histórica. Antecedentes y novedades del Plan de Caminos de Fomento Agrícola (Argentina, 1956)". En História: Debates e Tendencias, v. 18, №2, mayo-agosto 2018, pp. 260-275. Disponible en: http://seer.upf.br/index.php/rhdt/issue/view/605

${ }^{25}$ Dirección Nacional de Vialidad, extraído del Informe de la República Argentina para la segunda sesión de la Comisión Especial II del Consejo Interamericano Económico y Social: desarrollo agrícola y reforma agraria. 1963, p. 207.
} 
Gráfico 1: Redes viales de la provincia de Buenos Aires (en km), 1962.

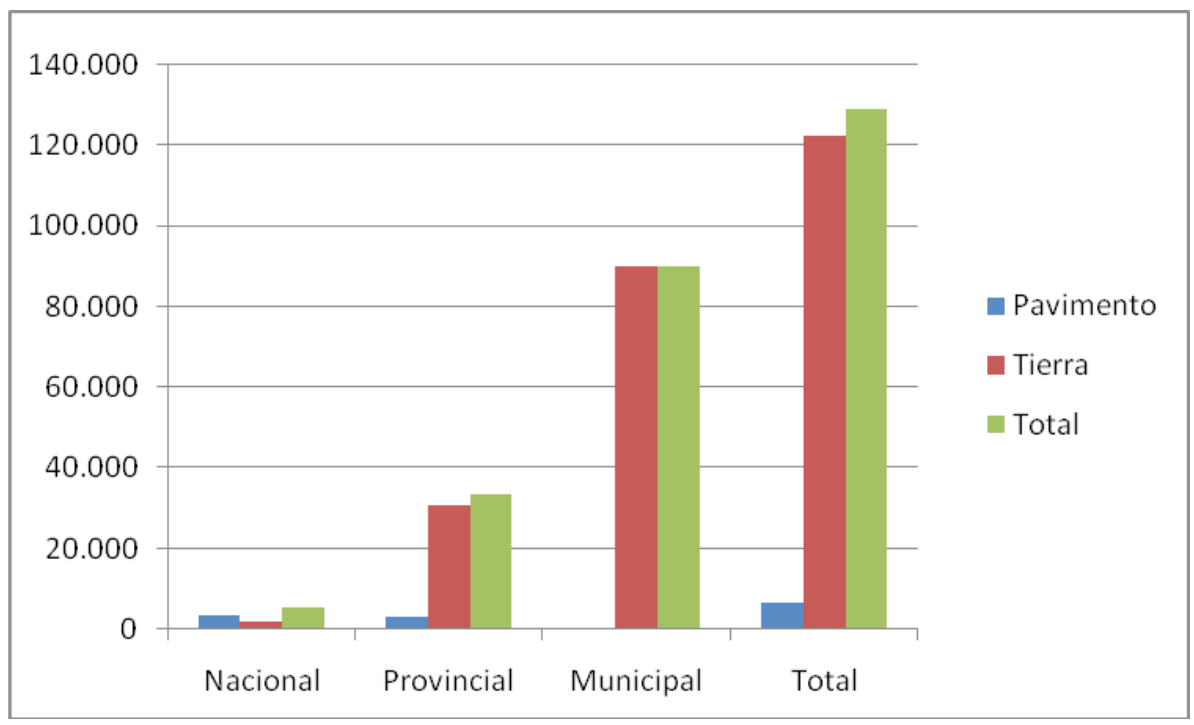

Fuente: VILLAR, Juan, op. cit. p. 177.

La proliferación de CC muestra la iniciativa vecinal, así como el papel positivo del Estado al proporcionar condiciones que mejoraran la capacidad de los apropiadores locales para participar en diseños institucionales efectivos que resolvieran problemas compartidos. Si bien estaban contemplados jurídicamente desde los años treinta ${ }^{26}$, fue a raíz del Plan de Caminos Fomento Agrícola y la legislación posterior tanto nacional como provincial, que los CC contaron con estímulos efectivos para su conformación. ${ }^{27}$ Antes, distintos factores habrían sido causa de su escaso desarrollo: fallas en las disposiciones reglamentarias, insuficiencia de la participación financiera oficial y falta de conocimiento de la legislación vigente. ${ }^{28}$

\footnotetext{
${ }^{26} \mathrm{~A}$ nivel nacional, estaban regidos por la ley 11.658/1932, en tanto que a nivel provincial, por la ley 4.117/1932 y los decretos 601/1934 y 623/1934. Ministerio de Obras Públicas de la Provincia de Buenos Aires. Leyes, Decretos, Resoluciones y demás disposiciones sobre vialidad en el territorio de la Provincia de Buenos Aires. La Plata, 1937.

${ }^{27}$ Resolución 2.300/56. Decreto 4.876/1967. Ministerio de Obras Públicas. Plan de Caminos de Fomento Agrícola. Buenos Aires, 1956, pp. 19-29. Provincia de Buenos Aires. Ministerio de Gobierno. Registro Oficial. Vol. VI, junio de 1967, pp. 123-126.

${ }^{28}$ Cámara Argentina de la Construcción. El problema vial. Conferencias y debates políticos organizados por la Cámara Argentina de la Construcción. Buenos Aires, 1952, pp. 204-205.
} 
En primer lugar, fue esencial el aporte financiero gubernamental, primero del 80\% y, a partir de 1967, del 50\% del costo completo de las obras. Eso pudo ser posible gracias a la coparticipación y al engrosamiento de partidas viales para provincias y municipios que, con marchas y contramarchas, testimoniaron una mayor preocupación vial. ${ }^{29}$ Dictado por el gobierno nacional, el decretoley 505/1958 fundó el Consejo Vial Federal y estableció una nueva escala de gravámenes para el impuesto a los combustibles, sustituyendo el importe fijo por un porcentaje, con el objeto de afrontar el proceso inflacionario. ${ }^{30}$ La ley 15.274/1960 creó el Fondo Nacional Complementario de Vialidad, constituido por impuestos a las cubiertas y los vehículos automotores cuyo peso bruto excediera de doce toneladas (aunque este último no fue percibido por la resistencia de los transportistas).

Además, a dos años de vigencia del Plan se propuso la ampliación de sus alcances, en beneficio no sólo del productor agrario, sino también del pecuario y minero. Dicha incorporación se traduciría en un cambio de nombre: Plan de Caminos de Fomento Agropecuario y Minero, aunque en la práctica no ocurrió. Lo que sí se materializó fue la dotación de financamiento estable. Como los recursos arbitrados por el decreto-ley de 1956 ( $m \$ n$ 1.500.000) quedaron totalmente insumidos en el ejercicio 1960/1961, el gobierno nacional asignó nuevos fondos para dotar al Plan de estructura permanente (antes era de cinco años). Para ello, la ley 15.273/1960 creó un impuesto que gravaba con el $0,5 \%$ a los productos y subproductos agrícolas y ganaderos con destino a exportación, el cual posteriormente fue elevado al 1\% (ley 16.450/1962).

En la provincia de Buenos Aires, luego de instituirse el Fondo Provincial de Vialidad (decreto-ley 7.823/1956), fue establecido el Régimen de Coparticipación Vial para las Municipalidades (decreto-ley 17.861/1957), novedoso sistema mediante el cual la Dirección de Vialidad de la Provincia de Buenos Aires entregaba a las Municipalidades un porcentaje de sus recursos propios con el objeto de que éstas lo aplicaran en el mejoramiento y conservación de los caminos de jurisdicción municipal, excluyendo -salvo excepciones- a aquellos que se encontraran en zonas urbanas o urbanizadas. ${ }^{31}$

\footnotetext{
${ }^{29}$ El derrotero legislativo sobre el vínculo entre vialidad y recursos es sinuoso y requiere un análisis pormenorizado. Aquí solo mencionaremos algunos hitos.

${ }^{30}$ Desde 1932, la principal fuente de recursos para las obras viales había sido la de los impuestos a los combustibles, en particular, el aplicado a la nafta. La recaudación se realizaba en base a un importe fijo que integraba el precio de venta de cada litro de combustible. A pesar de los sucesivos aumentos, el proceso inflacionario hizo que los recursos resultaran insuficiente para atender las necesidades. DNV. Memorias 1959-1962.
}

${ }^{31}$ Provincia de Buenos Aires. Ministerio de Gobierno. Registro Oficial. Vol. X, octubre de 1958, pp. 1067-1072. 
Así se les otorgaba respaldo financiero a las Municipalidades, en base al supuesto de que eran sus autoridades las que mejor conocían el problema vial de sus distritos. La distribución de fondos se efectuaría teniendo en cuenta la superficie, la producción agrícolo-ganadera y la inversión efectiva realizada con fondos propios. Para lograr la cooperación, el intercambio y la planificación orgánica de la labor de los municipios vecinos, se crearon doce Consejos Zonales correspondientes a cada una de las zonas camineras de la Dirección Provincial de Vialidad. Según el presidente del Primer Congreso Vial Municipal, Filiberto Bibliloni, la importancia del esfuerzo desarrollado podía medirse en el hecho de que en 1958, la cuota de Coparticipación Vial Municipal fue de 20 millones de pesos, en 1960 fue de 80 millones, en 1961 fue de 173 millones y en 1962 sería de 220 millones, habiendo puesto en cada caso las Municipalidades una cifra igual. ${ }^{32}$

Pero las instituciones políticas no se limitaron a la reglamentación o al suministro de una porción de los recursos, también asumieron responsabilidades de planificación y supervisión. Al respecto, vale destacar la tarea de las direcciones viales nacional y provincial: aprobaban los proyectos, facilitaban asesoramiento técnico, alquilaban equipos para la realización de las obras y efectuaban el monitoreo contable y técnico de las obras. Estas responsabilidades fueron acompañadas de la formación técnica, tal como lo demuestra la creación en 1957 de la Escuela de Ingeniería de Caminos, dependiente de la Dirección de Vialidad de la Provincia de Buenos Aires, que funcionó cómo ámbito de transmisión universitaria. Las comunas, por su parte, asumieron nuevas funciones: seleccionaban un representante para integrar la comisión ejecutiva de los CC y designaban una Comisión Vial municipal, ésta última encargada detectar necesidades vecinales, efectuar propuestas y supervisar a los CC.

Aun cuando en la solución de los problemas viales entró en juego un ente regulador, hacía falta un acuerdo institucional entre las partes. En este sentido, fue importante un tercer incentivo institucional: la definición de reglas de juego más precisas que en la legislación previa. Por ejemplo, las responsabilidades de la Comisión Ejecutiva o la modalidad de asignación de fondos. Afirmaba Enrique Humet, visepresidente de la DPV y director técnico de la Asociación Argentina de Carreteras": "Una de las novedades de este plan consiste en que se dejan de lado las jurisdicciones provinciales y comunales y se establece un sistema de trabajos -en beneficio de la celeridad- en que al

${ }^{32}$ Primer Congreso Vial Municipal, p. 47. 
mismo tiempo todas las organizaciones viales existentes aúnan sus esfuerzos. ${ }^{33}$ No obstante, si bien desconocemos litigios puntuales en torno al cumplimiento de las normas en estas asociaciones voluntarias, a priori es posible aseverar que la ley no contemplaba mecanismos para la resolución de conflictos. Sólo reconocía una sanción formal: la intervención por parte del Poder Ejecutivo a los fines de su reorganización y/o disolución. Como todo RUC, su manejo trasciende la cuestión técnica.

Por último, habría que ponderar otro incentivo la difusión de información (a través de medios de comunicación, INTA, etc.). Gracias a ella, es probable que los participantes de una situación pudieran a aprender de las experiencias de otros en escenarios similares, con lo cual el intercambio de información habría obrado a favor de los acuerdos alcanzados. La normativa fue dada a conocer en el ámbito rural, para lo cual colaboró activamente la Asociación Argentina de Carreteras con la impresión de afiches y folletos. ${ }^{34} \mathrm{El}$ plan de divulgación estuvo acompañado de reuniones en las localidades, en las que participaban autoridades locales y representantes viales provinciales y nacionales. ${ }^{35}$ Algunas empresas también se involucraron en la campaña, como la fábrica de tractores Concord, editó un folleto que, redactado con claro sentido didáctico, se refería a los distintos pasos necesarios para constituir un CC y sugería indicaciones prácticas para la ejecución de las obras. ${ }^{36}$

En suma, estos acuerdos institucionales fueron combinaciones fructíferas de agencias públicas y privadas. Al compartir voluntariamente los costos, los participantes aprendieron que era posible alcanzar objetivos conjuntos mediante acciones voluntarias y cooperativas que implicaban inversiones en tiempo y dinero. En este sentido, debe reconocerse que aun cuando los medios institucionales estaban a su disposición, los individuos compartían capacidades para resolver los problemas. En otras palabras, la experiencia requirió condiciones de sociabilidad y compromiso de la sociedad, lo cual amerita un análisis puntual. Por entonces, en los pueblos de base rural adquirían preeminencia las relaciones interpersonales y redes de amistades y favores, las que se asentaban en sistemas de roles y de nombres atribuidos de manera rígida a los individuos y que se reproducían sin modificaciones

\footnotetext{
${ }^{33}$ Carreteras. $\mathrm{N}^{\circ} 11$, julio-septiembre de 1957, p. 70.

${ }^{34}$ Carreteras. $\mathrm{N}^{\circ} 43$, julio-septiembre de 1967, p. 12.

${ }_{35}$ Por ejemplo, Noticias Camineras. № 36, abril de 1957, p. 5. Noticias Camineras. № 37, mayo de 1957, p. 7.

${ }^{36}$ Noticias Camineras. № 41, septiembre de 1957, p. 5.
} 
substanciales a través de las generaciones. ${ }^{37}$ La vida social se proyectaba en la esfera pública e incidía en el compromiso con la colectividad.

Esta constatación se vincula estrechamente con la lógica de Ostrom, para quien la clave está en relacionar recurso y comunidad. Como planteara César Rendueles, "los comunes fructifican allí donde no te puedes salir con facilidad de los compromisos asumidos, tanto porque no tienes incentivos para ello porque no es material o socialemente sencillo hacerlo". ${ }^{38}$ De allí que resultaría relevante rastrear un bagaje de experiencias históricas de coordinación social en el ámbito del manejo de los caminos rurales, factible de ser recuperada y reformulada en la actualidad.

\section{Reflexiones finales: una mirada al presente}

Lejos de suponer que hemos abarcado la esencia de la creación y el funcionamiento de los CC, complejos y dinámicos, en este trabajo nos hemos circunscipto a presentar un conjunto de variables como un marco de referencia para comprender la relevancia de los factores institucionales para el análisis de los caminos rurales en tanto RUC. En esta dirección, este sucinto y preliminar estudio ha puesto en evidencia ciertos atributos del entorno institucional que potencian la disposición de los individuos a cooperar con el grupo para la construción y la conservación de caminos en espacios locales y rurales. Con el foco colocado en el interior de la provincia de Buenos Aires, hemos advertido que el Plan de Caminos de Fomento Agrícola y las políticas subsiguientes marcaron un hito en la acción colectiva en pos de los caminos rurales, al transformar la estrucura de incentivos a los que se enfrentaban los productores agropecuarios. Si bien el Estado asumió el papel activo (con recursos técnicos, organizativos y económicos), debe contemplarse que las comunidades locales manifestaron poder de iniciativa al autoorganizarse en CC. Ceder a los actores locales (comunidades y municipios) el protagonismo en la gestión se convirtió en una manera de momotizar la acción ciudadana -fomentando así un sistema policéntrico-, aunque el Estado nacional y provincial mantenía el control sobre el dinero erogado.

La proliferación de CC a fines de los años cincuenta permite comprobar la viabilidad de instituciones locales para organizarse y gobernar el manejo

\footnotetext{
${ }^{37}$ ALBADALEJO, Christophe. "De la pampa agraria a la pampa rural: la reconstrucción de las 'localidades' y la invención del 'desarrollo rural local’”, En Párrafos Geográficos. vol. 5. № 1, 2006, p. 33. Disponible en: https://es.scribd.com/document/277272729/Albadalejo-De-La-Pampa-Gringa-a-La-Pampa-Rural

${ }^{38}$ RENDUELES, César y SUBIRATS, Joan. Los (bienes)comunes. ¿Oportunidad o espejismo?. Icaria Editorial. Barcelona, 2016, p. 71.
} 
de un recurso colectivo tan complejo como el camino rural. Conociendo este modelo, resulta evidente que su éxito es resultado del reconocimiento de la importancia de la colaboración en pos de un beneficio colectivo. Actualmente, el caso de la provincia de Córdoba ilustra claramente este punto: la organización y ya tradicional actuación consorcista es testimonio del logro de un mínimo nivel de solución al problema caminero. Por el contrario, desde mediados de la década del setenta en la provincia de Buenos Aires los municipios asumen esa responsabilidad con recursos obtenidos de la Tasa Vial (cobrada a los contribuyentes en función de la superficie de sus campos), y tercerizan las tareas a empresas privadas. Ante el centralismo institucional, el achicamiento de montos destinados a caminos rurales y la inexistencia de financiamiento a CC, resulta deficil que los productores realicen esfuerzos organizados. Frente al crítico panorama vial los expertos sugieren optimizar la gestión de conservación incorporando el compromiso de los interesados. A eso apunta el proyecto de ley presentado en 2016 sobre "Consorcios Camineros y de Servicios Rurales Municipales”, el cual fomenta la participación y la autogestión pero sin renunciar al Estado como motor y ejecutor de las políticas públicas. Esta iniciativa exhibe la visibilidad que adquirió el tema vial rural como una cuestión de gestión mixta. El reto será ahora integrar esfuerzos de gobernantes y especialitas para sistematizar experiencias empíricas y contribuir al desarrollo de la Argentina rural contemporánea.

Artigo recebido para publicação em 27/03/2019

Artigo aprovado para publicação em 02/05/2019 